\title{
The sonographic appearance and obstetric management of placenta accreta
}

This article was published in the following Dove Press journal:

International Journal of Women's Health

16 November 2012

Number of times this article has been viewed

\section{Charleen Sze-yan Cheung Ben Chong-pun Chan}

Department of Obstetrics and Gynaecology, Queen Mary Hospital, Hong Kong
Correspondence: Charleen Sze-yan Cheung Department of Obstetrics and Gynaecology, Queen Mary Hospital, 102, Pokfulam Road, Hong Kong Tel +852 22554267

Fax +852 28550947

Email charleensycheung@hku.hk
Abstract: Placenta accreta is a condition of abnormal placental implantation in which the placental tissue invades beyond the decidua basalis. It may invade into or even through the myometrium and adjacent organs, such as the urinary bladder. The incidence has been rising in recent years. It is one of the important obstetric complications nowadays, leading to significant maternal morbidity and mortality. In the past, this condition was often diagnosed at the time of delivery when massive and unexpected hemorrhage occurred. Hysterectomy, associated with significant physical and psychological consequences, was usually the only management option. As more obstetricians have become aware of this condition, early identification with antenatal imaging diagnostic technology has become possible. Ultrasound scan plays an important role in the antenatal diagnosis. Various sonographic features with different specificity and sensitivity have been described in the literature. In equivocal cases, magnetic resonance imaging may be helpful. With such information, more accurate counseling can be offered to the mothers and their families before delivery. The delivery can also be arranged at a favorable time and in an institution where multidisciplinary support is available. Input from a hematologist, interventional radiologist, intensive care physician, urology surgeon, and/or other specialist are desirable. Apart from hysterectomy, various forms of conservative management can also be considered when the diagnosis is made prior to delivery. Fertility can therefore be preserved. After delivery, with or without hysterectomy performed, psychological support to the mothers and their families is essential.

Keywords: ultrasonography, hemorrhage, hysterectomy

\section{Introduction}

Morbidly adherent placenta represents a spectrum of disorders characterized by abnormal adherence or penetration of the placenta into the uterine wall. Histologically, it has been defined according to the degree of pathological penetration. Placenta accreta refers to a superficial attachment without invasion into the myometrium. Placenta increta occurs when placental villi extend into the myometrium. In placenta percreta, the invasions extend deep beyond the uterine serosa. From a clinicosurgical point of view, different degrees of invasion may coexist in the same patient. The three types of abnormal placentation and their management are often collectively described in the literature. ${ }^{1,2}$

The vast majority of women with placenta accreta have an identifiable risk factor. ${ }^{3}$ Placenta previa and previous cesarean delivery are the major risk factors for placenta accreta. The risk increases with the number of previous cesarean sections. ${ }^{4,5}$ Myometrial trauma and scarring resulting from repeated dilatation and curettage, or other corrective 
surgeries also contribute to the risk of developing abnormal placental adherence. Advanced maternal age has also been identified as an independent risk factor. Others include smoking, grand multiparity, and recurrent miscarriages. . $^{2,6-8}$

The incidence of placenta accreta has been escalating, from a reported occurrence of one in 30,000 deliveries in 1950 to one in 2500 deliveries (a tenfold increase) in 1997.6,9 This marked increase has been attributed to the increase in cesarean section rates worldwide.

Placenta accreta remains a leading cause of maternal hemorrhage and obstetric hysterectomy. Up to $38 \%$ of postpartum hysterectomies were found to be associated with placenta accreta in a review by the UK Obstetric Surveillance System. ${ }^{10}$ Maternal morbidity and mortality are considerable. Related events and interventions include massive blood loss, dilutional or consumptive coagulopathy, blood transfusion, transfusionrelated reaction or acute injury, postpartum hysterectomy, cystotomy, intensive care, and prolonged hospitalization. Not only is there concern for the high demands on health resources and expenditure, concern about litigation for an adverse obstetric outcome is inevitable..$^{8,10-13}$

A recent study has forecasted that a continued rise in Cesarean section rates could lead to substantial increase in incidence of placenta previa-accreta and maternal death. ${ }^{14}$

Identification of risk factors, accurate antenatal and preoperative diagnosis, multidisciplinary management, and appropriate counseling will all aid in the overall management of women with placenta accreta and in reduction of maternal morbidity.

\section{Ultrasonography}

Ultrasonography remains a noninvasive, widely available and cost-effective modality of first-line diagnosis of placenta accreta in clinical practice.

Limitations to transabdominal ultrasound include the effect of maternal body habitus as well as its suboptimal visualization of the lower uterine cervix or area of placental invasion. The safety of transvaginal ultrasound in placenta previa has been accepted. It allows a closer view and more accurate examination of the lower uterine segment, leading to improved diagnostic accuracy in placenta previaaccreta. ${ }^{15,16}$

Since the 1980s, numerous ultrasound imaging techniques have been developed to assist in diagnosing morbidly adherent placenta antenatally. These include grayscale, color and/or three-dimensional power Doppler sonography. Various sonographic features and criteria for diagnosis have been suggested.

\section{Retroplacental sonolucent zone}

A normally occurring clear zone between the placenta and myometrium has been described ${ }^{17}$ This area is observed from 12 weeks and is believed to be associated with the dilated vessels of the decidua basalis. Deficiency and progressive loss of the decidua (Figure 1) has been proposed and confirmed histologically in placenta accreta. ${ }^{18}$ Obliteration of this sonolucent zone between the placenta and myometrium was first observed in the 1980s and confirmed in subsequent studies. ${ }^{19-21}$ However, the sensitivity of this sign in isolation remains low. A false positive rate of up to $50 \%$ has been reported. $^{22}$

\section{Vascular lacunae}

Multiple venous structures occurring throughout the myometrium and placenta in accreta were first described by Kerr de Mendonça in 1988. ${ }^{22}$ Subsequent observations of placental lakes were described as large and irregular ("Swiss cheese" appearance). These lacunae were not necessarily the areas of invasion. Presence of this sonographic sign has been reported to be associated with the highest positive predictive value for placenta accreta (Figure 2). When identified in the second and third trimesters, the sensitivity of this sign is $79 \%$, with a positive predictive value of $92 \% .^{3,15,20,23}$ The presence of lacunae was also found to be significantly associated with risks of disseminated intravascular coagulopathy, massive transfusions, and intensive care. ${ }^{24}$

The presence of sonographic criteria is not pathognomonic and should be interpreted with caution in the clinical setting. Although found to be of high sensitivity and positive predictive value, the presence of placenta lacunae and lack of sonolucent zone have (not infrequently) been observed in placenta previa without morbid adherence of placenta. ${ }^{25}$

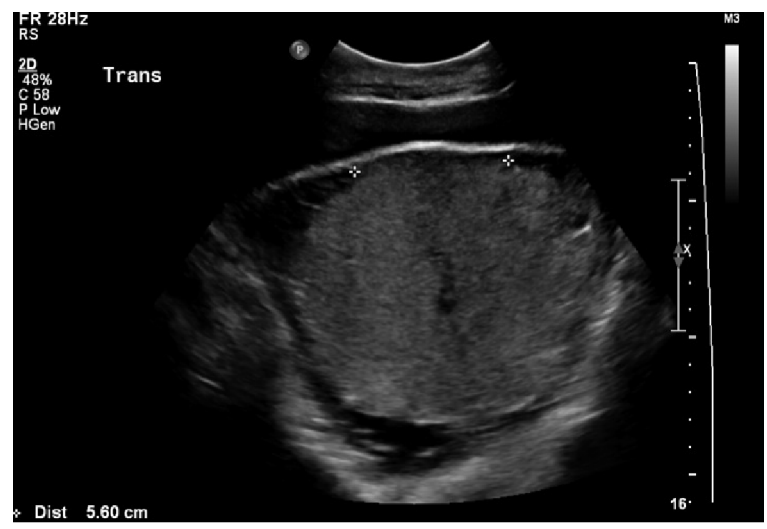

Figure I Deficiency of retroplacental sonolucent zone.

Note: Image courtesy of the Department of Diagnostic Radiology, Queen Mary Hospital, Hong Kong. 


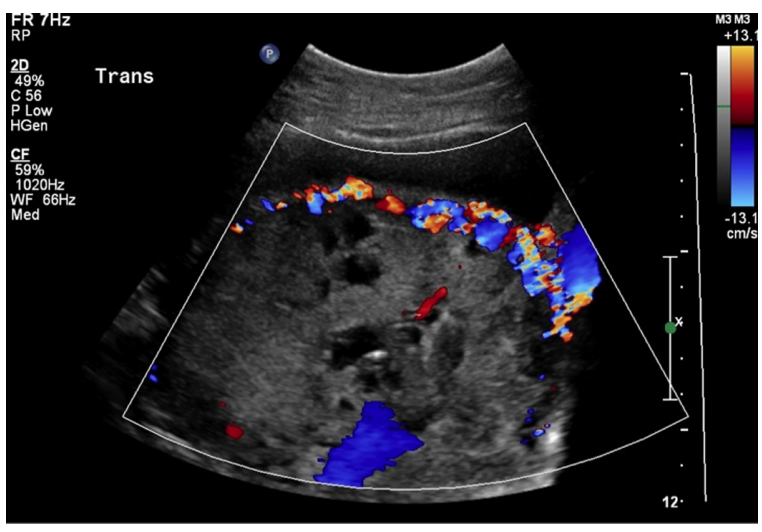

Figure 2 Vascular lacunae.

Note: Image courtesy of the Department of Diagnostic Radiology, Queen Mary Hospital, Hong Kong.

\section{Myometrial thinning}

Progressive thinning of the retroplacental myometrium indicates the proximity of placental tissue to the peritoneal serosa or surrounding viscera, particularly the bladder. Segmental myometrial thinning of $<1 \mathrm{~mm}$ is suggestive of an adherent placenta (Figure 3). Combined with presence of large placental lacunae, the sensitivity of this sign reaches nearly $100 \%$ and specificity is $72 \%-79 \%$, with a positive predictive value of $73 \%{ }^{26,27}$

\section{Interruption of bladder line}

Lack of myometrial tissue could result in thinning or disruption of the vesicouterine interphase, which has been found to be associated with greater compromise (Figure 4). In reality, distinguishing between irregularities of the bladder wall and placenta accreta may sometimes be difficult. ${ }^{20,21}$

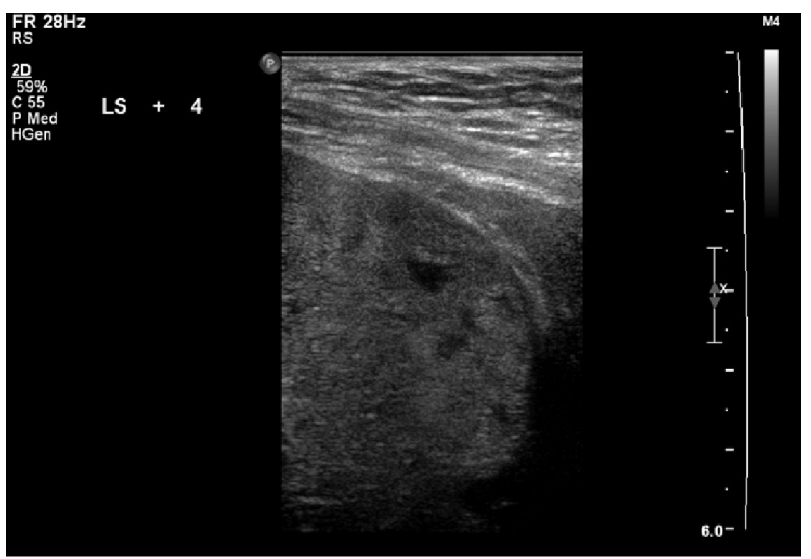

Figure 3 Myometrial thinning.

Note: Image courtesy of the Department of Diagnostic Radiology, Queen Mary Hospital, Hong Kong.

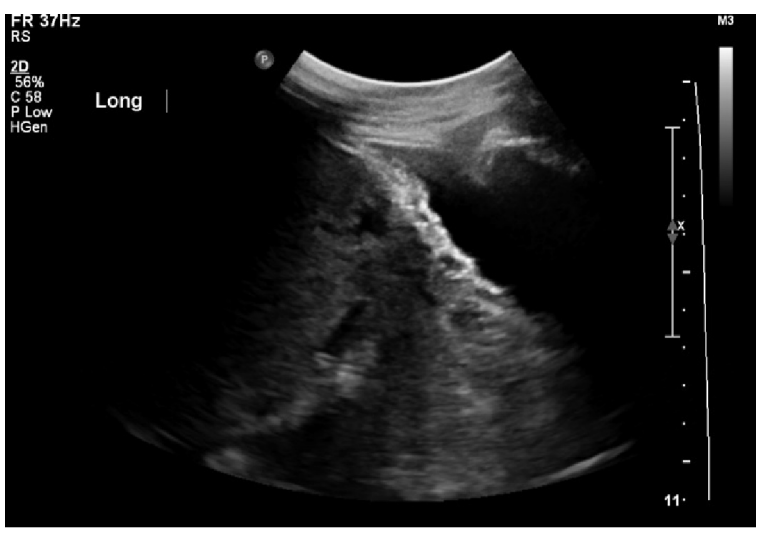

Figure 4 Interruption of bladder line.

Note: Image courtesy of the Department of Diagnostic Radiology, Queen Mary Hospital, Hong Kong.

\section{Presence of exophytic masses}

In extreme cases, the presence of extrauterine placental parenchyma can confirm the diagnosis of placenta percreta.

The use of ultrasound greyscale has been shown to be capable of diagnosing placenta accreta with sensitivity ranging from $87 \%-95 \%$, specificity of $76 \%-98 \%$, and a positive predictive value of $82 \%-93 \% .{ }^{2,28}$ The predictive value of ultrasound in the diagnosis of placenta accreta in the first trimester remains unclear. ${ }^{29}$ Table 1 summarizes the sonographic features of placenta accreta reported by various authors.

\section{Color Doppler imaging}

Color and power Doppler provide a higher specificity in the diagnosis of placenta accreta and in particular, the depth of invasion. A pattern of turbulent blood flow extending from the placenta into the surrounding tissues has been reported in placenta accreta. ${ }^{16}$ Other criteria include focal or diffuse

Table I Summary of sonographic features of placenta accrete

\begin{tabular}{|c|c|}
\hline $\begin{array}{l}\text { Sonographic features of placenta } \\
\text { accreta }\end{array}$ & Authors \\
\hline \multirow{4}{*}{$\begin{array}{l}\text { Deficiency of retroplacental sonolucent } \\
\text { zone }\end{array}$} & Pasto $\mathrm{ME}$ et al $^{19}$ \\
\hline & Hoffmann-Tretin JC et al ${ }^{18}$ \\
\hline & Finberg $\mathrm{HJ}$ et $\mathrm{al}^{20}$ \\
\hline & Hamanda S et $\mathrm{al}^{25}$ \\
\hline \multirow[t]{6}{*}{ Vascular lacunae } & Kerr de Mendonça L ${ }^{22}$ \\
\hline & Oyelese $Y$ et al ${ }^{15}$ \\
\hline & Comstock $\mathrm{CH}$ et $\mathrm{al}^{20}$ \\
\hline & Yang Jl et $\mathrm{al}^{24}$ \\
\hline & Baughman WC et al ${ }^{23}$ \\
\hline & Hamanda $\mathrm{S}$ et $\mathrm{al}^{25}$ \\
\hline \multirow[t]{2}{*}{ Myometrial thinning } & Hudon L et $\mathrm{al}^{26}$ \\
\hline & Twickler DM et al ${ }^{27}$ \\
\hline \multirow[t]{2}{*}{ Interruption of bladder line } & Finberg $\mathrm{HJ}$ et $\mathrm{al}^{21}$ \\
\hline & Comstock $\mathrm{CH}$ et $\mathrm{al}^{20}$ \\
\hline
\end{tabular}


intraparenchymal placental lacunar flow, vesicouterine serosa interphase hypervascularity, prominent retroplacental venous complex, and loss of retroplacental Doppler vascular signals. ${ }^{30}$ The diagnostic sensitivity reached $82 \%$, while positive predictive value was $87 \%$ in one study looking at use of Doppler. ${ }^{31}$

\section{Three-dimensional Doppler}

Reported features include numerous coherent vessels involving the whole vesicouterine serosa interphase on basal view; and hypervascularity, inseparable cotyledonal and intervillous circulations, chaotic branching, and detour vessels on lateral views. ${ }^{29,32}$

\section{Magnetic resonance imaging (MRI)}

Ultrasonography and MRI are comparable in diagnosing placenta accreta. The latter has additional value in detecting depth of placental invasion and depicting posterior placenta accreta. However, there is insufficient evidence to support routine MRI scanning of patients with sonographically suspected placenta accreta to improve management and outcome. MRI is often recommended when ultrasound findings are inconclusive. ${ }^{29,33-36}$ MRI findings suggestive of placenta accrete include uterine bulging, heterogeneous signal intensity within the placenta, dark intraplacental bands on T2-weighted images, tenting of the bladder, and direct visualization of placental invasion into pelvic structures. ${ }^{23}$ Figure 5 illustrates ultrasound examination with Doppler study showing a major anterior placenta previa accreta with bladder wall involvement. The MRI scan was also suggestive of deep myometrial invasion by placental tissue, but the bladder mucosa was intact.

\section{Obstetric management strategies Antenatal}

Anticipation and identification of risk factors is essential in developing safe management strategies. It has been recommended that women who had previous cesarean section

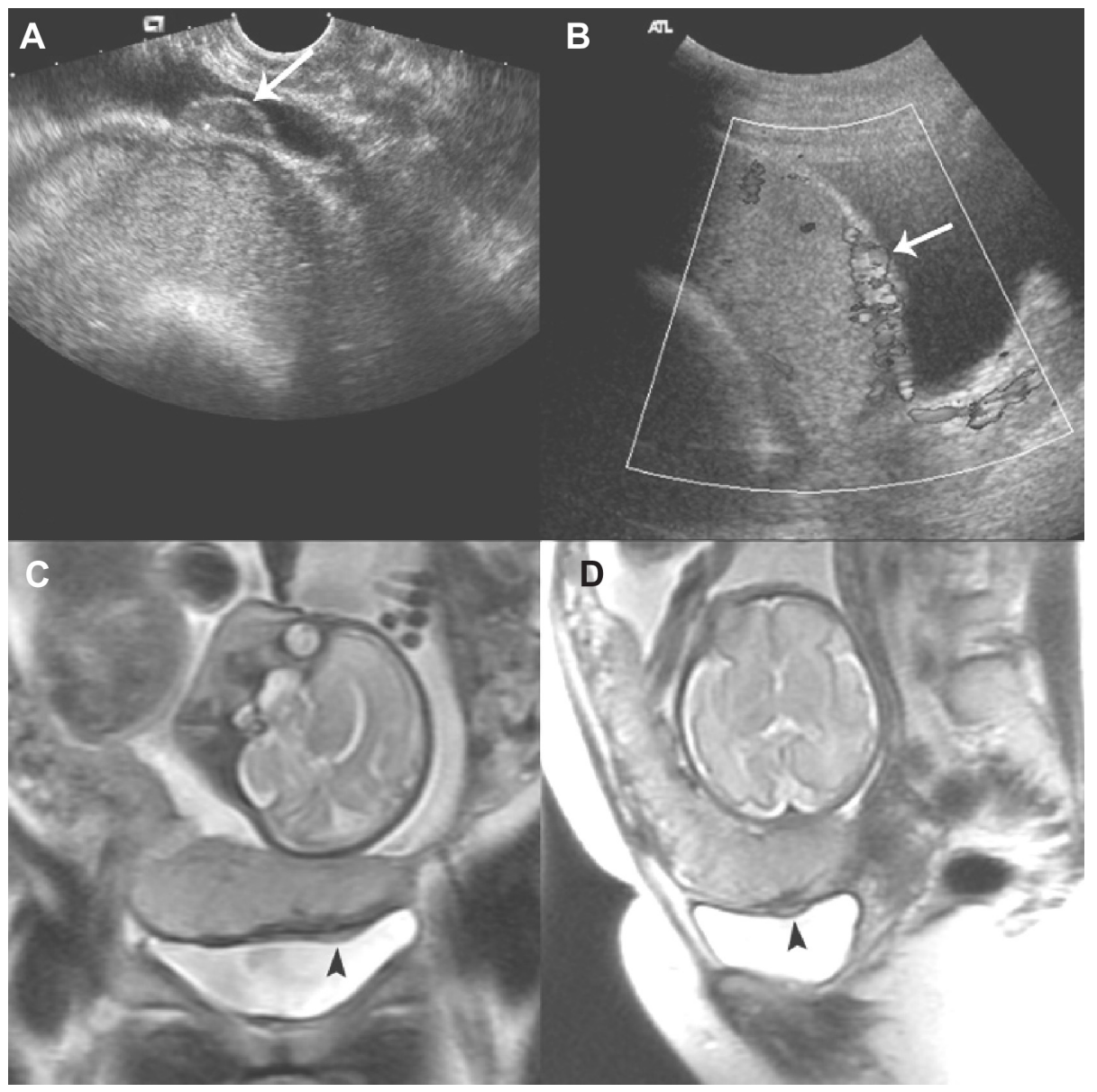

Figure 5 Ultrasound examination with Doppler study showing a major anterior placenta previa accreta with bladder wall involvement.

Notes: (A) and (B) -Transvaginal ultrasound scan images revealed no myometrial tissue between the lower uterine wall and the bladder. An abnormal vessel running within the bladder wall can also been seen (white arrows). (C) and (D) - Coronal and sagittal magnetic resonance images indicated a bulge at the bladder wall (black arrowheads). Image courtesy of the Department of Diagnostic Radiology, Queen Mary Hospital, Hong Kong.

Abbreviation: MRI, magnetic resonance imaging. 
should have placental localization to exclude placenta previa and further investigation to identify placenta accreta, if necessary. ${ }^{37,38}$

The management of morbidly adherent placenta is a real obstetric challenge and should be undertaken by a consultantled multidisciplinary team in a tertiary care institute. Delivery is ideally planned and arranged electively under controlled conditions with appropriate surgical and hematological facilities.

The presence of a consultant obstetrician and anesthesiologist at delivery, possible input from urology, gynecologic oncology, and vascular surgeons, blood products arrangement and prompt delivery, and access to intensive care constitute a care bundle in managing a patient with placenta accreta. $^{29,32,39}$

Optimal timing of a scheduled delivery depends on various clinical factors. Elective preterm delivery is often necessary because of pregnancy complications, like antepartum hemorrhage. The maternal benefits of earlier elective delivery must be balanced against the neonatal morbidity associated with premature birth. In the absence of antepartum hemorrhage or pregnancy complications, elective late-preterm delivery is acceptable to reduce the likelihood of emergency delivery at term. ${ }^{13,39}$

The adoption of conservative versus radical management is another important decision to be made in the planning process. Thorough preoperative counseling is crucial. The patient should be adequately counseled about the risks of catastrophic hemorrhage, blood transfusion, and visceral involvement. Possible interventions such as hysterectomy, ureteric stenting and cystotomy, or conservative measures (including leaving the placenta in situ, use of cell salvage, and interventional radiology) should also be discussed.

A preoperative checklist would be helpful in confirming necessary preparations and for identifying contact persons in case perioperative assistance is required.

\section{Intrapartum}

Anesthetic considerations include large-bore intravenous access, rapid replacement of fluid and blood, hemodynamic monitoring facilities, prevention of hypothermia, and thromboembolic prophylaxis. ${ }^{29,40}$

Dorsal lithotomy positioning with hip abduction but limited flexion can enable direct evaluation of intraoperative vaginal bleeding, and allow uterine balloon placement if needed.

Immediate preoperative ultrasound mapping of the placental location aids in determining the optimal approach to the abdominal wall and uterine incisions. It is recommended that uterine incision be made away from the placenta during entry to the uterine cavity. Incision through the placenta and attempt to deliver the placenta often result in significant hemorrhage. Figure 6 illustrates a thin and very vascular uterine lower segment at the time of cesarean section. The rich vascularity usually correlates with the position of placentation. Attempt to remove the placenta leads to disruption of the infiltrated bed and is associated with increased maternal morbidity. It has been suggested that it may be sensible to complete the delivery of the infant and proceed to an intended hysterectomy with the placenta left in situ. ${ }^{13,29,38,41,42}$ A total rather than subtotal hysterectomy is advocated because of the risk of hemorrhage from lower-segment invasions. For the same reason, internal iliac artery ligation is associated with significant risk of failure in managing postpartum hemorrhage in placenta accreta because of the collateral arterial supplies. In cases where subtotal hysterectomy is performed, peritoneal closure over the cervical stump should be avoided as further hemorrhage may be concealed and unnoticed. ${ }^{3}$

Interventional radiology does play an important role in offering prophylactic measures to reduce uterine flow and prevent ongoing hemorrhage. Preoperative placement of a catheter in the internal iliac or uterine arteries, with or without balloon inflation at the time of delivery, or embolization after cesarean section can be performed. ${ }^{39,43}$ Higher failure of embolization in placenta accreta was observed when compared with its use for postpartum hemorrhage due to other causes, like uterine atony or retained products of gestation. A recent systematic review of uterus-preserving treatment modalities ${ }^{1}$ revealed that uterine artery embolization for placenta accreta could achieve a subsequent menstruation

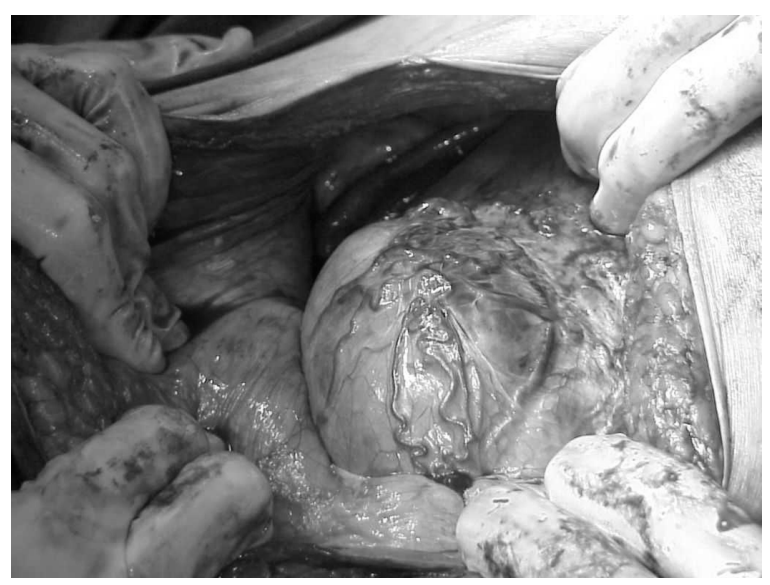

Figure 6 Thin and very vascular uterine lower segment at the time of cesarean section.

Note: The rich vascularity usually correlates with the position of placentation. 
rate of $62 \%$ and pregnancy rate of $15 \%$, and secondary hysterectomy rate of $18 \%$. Most of the studies involved small numbers and we are still awaiting results from further larger prospective series. ${ }^{44,45}$

In selected groups of women, conservative management can be considered. The criteria for such an approach include the possibility of preoperative consultation, hemodynamic stability without significant blood loss, a wish to preserve fertility, and the availability of resources and expertise to follow up and manage late postpartum complications. ${ }^{45}$ Conservative management aims to avoid hysterectomy by leaving the placenta in situ with or without additional measures, including arterial embolization, application of compression sutures, and segmental resection of the myometrial tissues followed by repair of the defect or uterine reconstruction. Lack of comparative studies on the different surgical techniques has resulted in wide variation in the approach adopted. Use of tissue sealants or even mesh has been reported, but to date, there is insufficient evidence on their effectiveness and safety. ${ }^{45-47}$

In a systematic review, ${ }^{1}$ expectant management in patients with invasive placentation is associated with a $67 \%$ rate of achieving subsequent pregnancy and a $19 \%$ rate of secondary hysterectomy at the same time.

\section{Postpartum}

Patients with placental accreta and especially those requiring hysterectomy for postpartum hemorrhage are at risk for complications in relation to intrapartum hypotension and persistent coagulopathy. Collaboration with intensive care physicians and the monitoring of vital signs and organ functions postoperatively is of paramount importance. Should there be hemodynamic instability or suspicion of hemoperitoneum, computed tomography (CT) or MRI should be undertaken and followed by exploratory laparotomy without delay. Persistent hematuria or anuria should alert clinicians of possible unrecognized urinary tract injury. Transient or permanent Sheehan syndrome is a known complication of massive postpartum hemorrhage. Hyponatremia may be an early sign for this. ${ }^{29}$

Secondary infection, sepsis, postpartum hemorrhage, and disseminated intravascular coagulopathy are the major clinical concerns after leaving the placenta in situ. Close surveillance and ready access to medical assessment and resuscitation are the key prerequisites to conservative management. Prophylactic broad-spectrum antibiotics and uterotonic agents are often recommended, although a consensual guideline has yet to be established. Whether the placenta should be removed in the postpartum period or left to resorb or be expelled spontaneously remains controversial. Serum human chorionic gonadotropin and Doppler ultrasound may be utilized to assess the cessation of placental vascularity for consideration of interval removal, but the clinical correlation remains undetermined. ${ }^{48}$

Methotrexate has been proposed as a conservative measure for retained placenta with morbid adherence. Methotrexate, being a folate antagonist, is not without side effects and is contraindicated in breastfeeding. It is effective against proliferating trophoblasts, but its action on degenerative placenta after delivery remains questionable and diverse in different series. In general, outcomes do not differ significantly with or without use of methotrexate. ${ }^{49,50}$

Adequate support and assessment of psychological wellbeing of the patient after major obstetric events are sometimes overlooked but indispensable. Debriefing sessions should be carried out with the patient and family at appropriate intervals. Adequate explanation and effective communication helps to reduce the risk of medical litigation.

\section{Conclusion}

Placenta accreta has been evolving into a more common complication in modern obstetrics. The rising incidence is partly caused by our changing obstetric practice in terms of cesarean delivery rate, and it is one of the consequences we have to encounter from now onwards. The identification of high-risk group mothers, based on history, during the antenatal period is important and facilitates the diagnosis of this condition by imaging techniques, mainly ultrasonography. Various sonographic features have been reported and a combination of these features may sharpen the accuracy of the diagnosis. The diagnostic value of magnetic resonance imaging for placenta accreta remains controversial. When the antenatal diagnosis of placenta accreta has been made, the mothers should be under care of a consultant obstetrician-led team throughout and receive informative counseling prior to delivery. Elective cesarean delivery should be arranged in an institution with multidisciplinary support. Conservative management can be considered mainly for mothers with the wish to preserve fertility, although delayed hysterectomy in the postnatal period is still a possibility. For mothers with a completed family, a lower threshold for hysterectomy may be desirable. Close monitoring after the operation, preferably in an intensive care unit or high dependency unit, is of paramount importance. Psychological support to the mothers, especially those who had a hysterectomy performed, and their families is essential. 


\section{Disclosure}

All authors hereby declare that there is no conflict of interest related to the work for this paper.

\section{References}

1. Steins Bisschop CN, Schaap TP, Vogelvang TE, Scholten PC. Invasive placentation and uterus preserving treatment modalities: a systematic review. Arch Gynecol Obstet. 2011;284(2):491-502.

2. Palacios-Jaraquemada JM. Diagnosis and management of placenta accreta. Best Pract Res Clin Obstet Gynaecol. 2008;22(6):1133-1148.

3. Doumouchtsis SK, Arulkumaran S. The morbidly adherent placenta: an overview of management options. Acta Obstet Gynecol Scand. 2010;89(9):1126-1133.

4. Clark SL, Koonings PP, Phelan JP. Placenta previa/accreta and prior cesarean section. Obstet Gynecol. 1985;66(1):89-92.

5. To WW, Leung WC. Placenta previa and previous cesarean section. Int J Gynaecol Obstet. 1995;51(1):25-31.

6. Miller DA, Chollet JA, Goodwin TM. Clinical risk factors for placenta previa-placenta accreta. Am J Obstet Gynecol. 1997;177(1):210-214.

7. Esakoff TF, Sparks TN, Kaimal AJ, et al. Diagnosis and morbidity of placenta accreta. Ultrasound Obstet Gynecol. 2011;37(3):324-327.

8. Gielchinsky Y, Rojansky N, Fasouliotis SJ, Ezra Y. Placenta accreta - summary of 10 years: a survey of 310 cases. Placenta. 2002;23(2-3):210-214.

9. Read JA, Cotton DB, Miller FC. Placenta accreta: changing clinical aspects and outcome. Obstet Gynecol. 1980;56(1):31-34.

10. Knight M; UKOSS. Peripartum hysterectomy in the UK: management and outcomes of the associated haemorrhage. BJOG 2007;114(11):1380-1387.

11. Wilkinson H; Trustees and Medical Advisors. Saving mothers' lives. Reviewing maternal deaths to make motherhood safer: 2006-2008. BJOG. 2011;118(11):1402-1403; discussion 3-4.

12. Hull AD, Moore TR. Multiple repeat cesareans and the threat of placenta accreta: incidence, diagnosis, management. Clin Perinatol. 2011;38(2):285-296.

13. Eller AG, Porter TF, Soisson P, Silver RM. Optimal management strategies for placenta accreta. BJOG. 2009;116(5):648-654.

14. Solheim KN, Esakoff TF, Little SE, Cheng YW, Sparks TN, Caughey $\mathrm{AB}$. The effect of cesarean delivery rates on the future incidence of placenta previa, placenta accreta, and maternal mortality. J Matern Fetal Neonatal Med. 2011;24(11):1341-1346.

15. Oyelese Y, Smulian JC. Placenta previa, placenta accreta, and vasa previa. Obstet Gynecol. 2006;107(4):927-941.

16. Lerner JP, Deane S, Timor-Tritsch IE. Characterization of placenta accreta using transvaginal sonography and color Doppler imaging. Ultrasound Obstet Gynecol. 1995;5(3):198-201.

17. Callen PW, Filly RA. The placental-subplacental complex: a specific indicator of placental position on ultrasound. $J$ Clin Ultrasound. 1980;8(1):21-26.

18. Hoffman-Tretin JC, Koenigsberg M, Rabin A, Anyaegbunam A. Placenta accreta. Additional sonographic observations. J Ultrasound Med. 1992;11(1):29-34.

19. Pasto ME, Kurtz AB, Rifkin MD, Cole-Beuglet C, Wapner RJ, Goldberg BB. Ultrasonographic findings in placenta increta. J Ultrasound Med. 1983;2(4):155-159.

20. Comstock CH, Love JJ Jr, Bronsteen RA, et al. Sonographic detection of placenta accreta in the second and third trimesters of pregnancy. $\mathrm{Am}$ J Obstet Gynecol. 2004;190(4):1135-1140.

21. Finberg HJ, Williams JW. Placenta accreta: prospective sonographic diagnosis in patients with placenta previa and prior cesarean section. J Ultrasound Med. 1992;11(7):333-343.

22. Kerr de Mendonça L. Sonographic diagnosis of placenta accreta. Presentation of six cases. J Ultrasound Med. 1988;7(4):211-215.

23. Baughman WC, Corteville JE, Shah RR. Placenta accreta: spectrum of US and MR imaging findings. Radiographics. 2008;28(7):1905-1916.
24. Yang JI, Lim YK, Kim HS, Chang KH, Lee JP, Ryu HS. Sonographic findings of placental lacunae and the prediction of adherent placenta in women with placenta previa totalis and prior Cesarean section. Ultrasound Obstet Gynecol. 2006;28(2):178-182.

25. Hamada S, Hasegawa J, Nakamura M, et al. Ultrasonographic findings of placenta lacunae and a lack of a clear zone in cases with placenta previa and normal placenta. Prenat Diagn. 2011;31(11): $1062-1065$.

26. Hudon L, Belfort MA, Broome DR. Diagnosis and management of placenta percreta: a review. Obstet Gynecol Surv. 1998;53(8): 509-517.

27. Twickler DM, Lucas MJ, Balis AB, et al. Color flow mapping for myometrial invasion in women with a prior cesarean delivery. J Matern Fetal Med. 2000;9(6):330-335.

28. Shih JC, Palacios Jaraquemada JM, Su YN, et al. Role of threedimensional power Doppler in the antenatal diagnosis of placenta accreta: comparison with gray-scale and color Doppler techniques. Ultrasound Obstet Gynecol. 2009;33(2):193-203.

29. Publications Committee, Society for Maternal-Fetal Medicine, Belfort MA. Placenta accreta. Am J Obstet Gynecol. 2010;203(5):430-439.

30. Allahdin S, Voigt S, Htwe TT. Management of placenta praevia and accreta. J Obstet Gynaecol. 2011;31(1):1-6.

31. Chou MM, Ho ES, Lee YH. Prenatal diagnosis of placenta previa accreta by transabdominal color Doppler ultrasound. Ultrasound Obstet Gynecol. 2000;15(1):28-35.

32. rcog.org.uk [homepage on the Internet]. Placenta praevia, placenta praevia accreta and vasa praevia: diagnosis and management. London: Royal College of Obstetricians and Gynaecologists.Green-top Guideline No 27; 2011 [updated May 1, 2011]. Available from: http:// www.rcog.org.uk/womens-health/clinical-guidance/placenta-praeviaand-placenta-praevia-accreta-diagnosis-and-manageme. Accessed September 28, 2012.

33. Masselli G, Brunelli R, Casciani E, et al. Magnetic resonance imaging in the evaluation of placental adhesive disorders: correlation with color Doppler ultrasound. Eur Radiol. 2008;18(6):1292-1299.

34. Dwyer BK, Belogolovkin V, Tran L, et al. Prenatal diagnosis of placenta accreta: sonography or magnetic resonance imaging? J Ultrasound Med. 2008;27(9):1275-1281.

35. Levine D, Hulka CA, Ludmir J, Li W, Edelman RR. Placenta accreta: evaluation with color Doppler US, power Doppler US, and MR imaging. Radiology. 1997;205(3):773-776.

36. Warshak CR, Eskander R, Hull AD, et al. Accuracy of ultrasonography and magnetic resonance imaging in the diagnosis of placenta accreta Obstet Gynecol. 2006;108(3 Pt 1):573-581.

37. Lewis G, editor. Saving Mothers'Lives: Reviewing Maternal Deaths to Make Motherhood Safer-2003-2005. The Seventh Report of the Confidential Enquiries into Maternal Deaths in the United Kingdom. London: Confidential Enquiry into Maternal and Child Health (CEMACH); 2007.

38. ACOG Committee on Obstetric Practice. ACOG Committee opinion. Number 266, January 2002: placenta accreta. Obstet Gynecol. 2002;99(1):169-170.

39. Hull AD, Resnik R. Placenta accreta and postpartum hemorrhage. Clin Obstet Gynecol. 2010;53(1):228-236.

40. Snegovskikh D, Clebone A, Norwitz E. Anesthetic management of patients with placenta accreta and resuscitation strategies for associated massive hemorrhage. Curr Opin Anaesthesiol. 2011;24(3): 274-281.

41. Yap YY, Perrin LC, Pain SR, Wong SF, Chan FY. Manual removal of suspected placenta accreta at cesarean hysterectomy. Int J Gynaecol Obstet. 2008;100(2):186-187.

42. Hayes E, Ayida G, Crocker A. The morbidly adherent placenta: diagnosis and management options. Curr Opin Obstet Gynecol. 2011;23(6):448-453.

43. Ophir E, Singer-Jordan J, Odeh M, et al. Abnormal placental invasiona novel approach to treatment case report and review. Obstet Gynecol Surv. 2009;64(12):811-822. 
44. rcog.org.uk [hompage on the Internet]. The role of emergency and elective interventional radiology in postpartum haemorrhage. London: Royal College of Obstetricians and Gynaecologists. Good Practice No 6; 2007 [updated June 1, 2007]. Available from: http://www.rcog. org.uk/womens-health/clinical-guidance/role-emergency-and-electiveinterventional-radiology-postpartum-haem. Accessed September 28, 2012.

45. Welsh AW, Ellwood D, Carter J, Peduto AJ, Vedelago J, Bennett M. Opinion: integration of diagnostic and management perspectives for placenta accreta. Aust N Z J Obstet Gynaecol. 2009;49(6): 578-587.

46. Wohlmuth CT, Dela Merced J. Gelatin-thrombin hemostatic matrix in the management of placental site postpartum hemorrhage: a case report. J Reprod Med. 2011;56(5-6):271-273.
47. Palacios-Jaraquemada JM, Fiorillo A, von Petery F, Colaci D, Leguizamón G. Uterine repair and successful pregnancy after myometrial and placental rupture with massive haemoperitoneum. BJOG. 2009;116(3):456-460.

48. Matsumura N, Inoue T, Fukuoka M, Sagawa N, Fujii S. Changes in the serum levels of human chorionic gonadotropin and the pulsatility index of uterine arteries during conservative management of retained adherent placenta. J Obstet Gynaecol Res. 2000;26(2):81-87.

49. Arulkumaran S, Ng CS, Ingemarsson I, Ratnam SS. Medical treatment of placenta accreta with methotrexate. Acta Obstet Gynecol Scand. 1986;65(3):285-286.

50. Mussalli GM, Shah J, Berck DJ, Elimian A, Tejani N, Manning FA. Placenta accreta and methotrexate therapy: three case reports. J Perinatol. 2000;20(5):331-334.

\section{Publish your work in this journal}

The International Journal of Women's Health is an international, peerreviewed open-access journal publishing original research, reports, reviews and commentaries on all aspects of women's healthcare including gynecology, obstetrics, and breast cancer. Subject areas include: Chronic conditions (migraine headaches, arthritis, osteoporosis);
Endocrine and autoimmune syndromes; Sexual and reproductive health; Psychological and psychosocial conditions. The manuscript management system is completely online and includes a very quick and fair peer-review system. Visit http://www.dovepress.com/ testimonials.php to read real quotes from published authors. 